\title{
Not Mere Lexicographic Cosmetics: The Compilation and Structural Features of Isichazamazwi SezoMculo
}

\author{
Nobuhle Moyo, African Languages Research Institute, University of \\ Zimbabwe, Harare, Zimbabwe (noxy_auree@yahoo.co.uk) \\ and \\ Dion Nkomo, Multilingualism Education Project, Centre for Higher \\ Education Development, University of Cape Town; and Department of \\ Afrikaans and Dutch, Stellenbosch University, Stellenbosch, \\ Republic of South Africa (deeouf@yahoo.co.uk)
}

\begin{abstract}
This article offers a brief overview of the compilation of the Ndebele music terms dictionary, Isichazamazwi SezoMculo (henceforth the ISM), paying particular attention to its structural features. It emphasises that the reference needs of the users as well as their reference skills should be given a determining role in all lexicographic decisions leading to the publication of a dictionary. Dictionary structure should, therefore, be conceived and evaluated in terms of its data constituents and the accessibility of these data. Accordingly, this article demonstrates that the structure of the ISM is not a case of mere cosmetics but a lexicographic mode of communication between the dictionary compilers and users who are participants in a lexicographic communication process. In this way, the article highlights some of the challenges encountered during the compilation of the ISM and the strategies the compilers employed to facilitate the communication process between the lexicographers and the users regarding dictionary contents and the arrangement thereof. From such a perspective, this article may provide useful insights for LSP lexicography in African languages, prospects of which are based on the increased need for knowledge acquisition and dissemination as well as the multilingual nature of African societies.
\end{abstract}

Keywords: LSP LEXICOGRAPHY, DICTIONARY STRUCTURE, MEGASTRUCTURE, MACROSTRUCTURE, MICROSTRUCTURE, MEDIOSTRUCTURE, REFERENCE NEEDS, REFERENCE SKILLS, OUTER TEXTS, LEMMATA, DICTIONARY ARTICLE

Opsomming: Nie slegs leksikografiese kosmetiek nie: Die samestelling en strukturele eienskappe van Isichazamazwi SezoMculo. Hierdie artikel bied 'n kort oorsig van die samestelling van die Ndebelewoordeboek van musiekterme Isichazamazwi SezoMculo (voortaan die ISM) deur besondere aandag te gee aan sy strukturele eienskappe. Dit beklemtoon dat die naslaanbehoeftes van die gebruikers sowel as hulle naslaanvaardighede 'n bepalende rol gegee behoort te word in alle leksikografiese besluite wat tot die publikasie van 'n woordeboek lei. Woordeboekstruktuur behoort derhalwe beplan en beoordeel te word ooreenkomstig sy databestanddele en die toeganklikheid van hierdie data. Hierdie artikel toon gevolglik dat die struktuur van die ISM nie net 'n geval van blote kosmetiek is nie, maar 'n leksikografiese kommunikasiewyse tussen die woordeboeksamestellers en -gebruikers wat deelnemers is in 'n leksikografiese kommunikasieproses. Op hierdie manier belig die artikel 'n aantal van die uitdagings wat teenge- 
kom is tydens die samestelling van die ISM en die strategieë wat die samestellers gebruik het om die kommunikasieproses tussen die leksikograwe en die gebruikers betreffende woordeboekinhoud en die ordening daarvan te vergemaklik. Vanuit so 'n perspektief kan hierdie artikel nuttige insigte verskaf in TSD-leksikografie in Afrikatale, vooruitsigte wat gebaseer is op die toenemende behoefte aan kennisverwerwing en -verspreiding sowel as die veeltalige aard van Afrikagemeenskappe.

Sleutelwoorde: TSD-LEKSIKOGRAFIE, WOORDEBOEKSTRUKTUUR, MEGASTRUKTUUR, MAKROSTRUKTUUR, MIKROSTRUKTUUR, MEDIOSTRUKTUUR, NASLAANBEHOEFTES, NASLAANVAARDIGHEDE, BUITETEKSTE, LEMMAS, WOORDBOEKARTIKEL

\section{Introduction}

This article offers a general overview of the compilation of a Ndebele dictionary of music terms, Isichazamazwi SezoMculo (henceforth the ISM), but its main focus is on the structure of this dictionary. Dictionary structure is seen as a system of communication between the compilers and users. Such an approach is critical in modern-day lexicography. To start with, the purpose of any lexicographic project should be to satisfy the needs of the target users (Gouws 1996: 100), since "all dictionaries are motivated by and judged against the lexical needs of the language user whom they serve" (Hartmann 1983: 5). The lexicographer may claim to have satisfied the needs of his/her users by providing the relevant data categories required to address the problems which initiate dictionary consultation. However, the following should be taken into account:

Not merely information needs of different categories of users are important. An equally important factor is their ability to find and make use of the given information (Svensén 1993: 10).

The data on offer in the dictionary should be presented in such a way that the knowledgeable target user can access it in order to retrieve the kind of information that motivated a given dictionary consultation procedure (Gouws and Prinsloo 2005: 165).

A well-formulated dictionary structure is the only way of ensuring that the users receive the maximum assistance from a dictionary. Thus, Yong and Peng (2007: 83) assert that:

Effective lexicographic communication requires the communicative system and its subsystems to be coordinated and structured in such ways as to facilitate interaction between the compiler and the user and to enhance ready access to different parts of the dictionary where the required information is located.

At the planning stages of dictionary production, the lexicographer needs to focus on the reference needs and reference skills of the target users by constructing a user profile (Bergenholtz and Tarp 1995, 2003; Tarp 2000, 2002, 2004). Although the authors of this article cannot give a detailed account of 
such planning regarding the ISM since they joined the project after its planning stages, they hope to show convincingly that the procedures they adopted after taking over the project, especially regarding the structural aspects of the dictionary, were motivated by the intention to satisfy the needs of the target users. While the decisions of the editors are largely reflected in the ISM, it should be noted that the style guide drawn up by the initiators of the project was always the point of departure. Some members of the initial editorial team and the reference working group also continued to assist in various ways until the publication of the dictionary.

Some of the challenges related to the typological nature of the ISM are discussed in Section 2. This will hopefully present some insights into specialised lexicography (henceforth LSP lexicography) especially for African language communities. The increased growth of knowledge in various subject fields owing to global technological developments as well as the need to nurture multilingualism in countries such as South Africa increases prospects for LSP lexicography in African languages. Together with the general lexicographic principles, the experiences of other LSP lexicographic projects such as the ISM may provide the necessary guidance. Section 3 discusses the frame structure, also called the megastructure, of the dictionary. The front-matter components of the ISM are subsequently described in Section 4. This is followed in Section 5 by the discussion of the macrostructure of the dictionary. The microstructure is then described in Section 6. The back matter is the subject of Section 7. This is followed by a description of the mediostructure in Section 8 , the final one before the conclusion.

\section{Some Challenges of a Typological Nature in the Compilation of the ISM}

The ISM is the first specialised dictionary (henceforth LSP dictionary) in Ndebele. It appeared in 2006, five years after the publication of the first monolingual Ndebele dictionary Isichazamazwi SesiNdebele (henceforth the ISN). Like the ISN, it was also published under the auspices of the African Languages Lexical (ALLEX) Project which led to the establishment of the African Languages Research Institute (ALRI). Unlike the ISN which attempts a general lexicographic coverage and treatment of the Ndebele vocabulary, the ISM covers the music domain in Ndebele. Its target-user groups are mainly music students, lecturers, teachers and other practitioners who need to interpret and understand music genres, instruments and other music concepts in Ndebele. Such a group of users generally shares a low level of dictionary culture with the entire Ndebele community. To most of these users, the ISM arguably became the first Ndebele dictionary to which they were introduced as they have remained unacquainted with the ISN published five years earlier. This is an indication of a poor dictionary culture, which is not peculiar to Ndebele, but generally prevalent in many African language communities. 
The very fact that the ISM is an LSP dictionary required special knowledge of the music domain. The editors, including their predecessors in the ISM project, did not possess such expert knowledge adequate for lexicographic purposes. The production of LSP dictionaries requires the combined effort of specialists in the specific subject field as well as lexicographic expertise (Bergenholtz and Tarp 1995, 2003; Tarp 2000, 2002). Although the ISM compilers possessed adequate lexicographic training, they had to rely on experts in the music industry and music education to produce a dictionary of substantial quality. They benefited from the expertise of a reference working group which comprised Ndebele-speaking music lecturers, music practitioners, linguists and individuals who, one way or another, are involved in music teaching and linguistic research.

The dictionary has a trilingual dimension. While Ndebele is the lemmatising and explicating language, Shona and English translation equivalents are provided. As a result, the ISM is generally, though erroneously, regarded as a trilingual dictionary. Scholars such as Burkhanov (2004), Gouws (2004a) and Hartmann and James (1998: 14) have argued in a convincing way that the provision of translation equivalents in a dictionary does not typologically make that dictionary bi- or multilingual. The main argument is that not every dictionary which provides translation equivalents may serve the typical functions of bi- or multilingual dictionaries. Nevertheless, this trilingual dimension of the ISM posed a number of challenges during its production.

The evident challenges encountered in the compilation of the ISM in respect of the trilingual dimension related to the issue of translation equivalents. This affected the formulation of the dictionary basis at the initial compilation stages. Firstly, the dictionary had to include terms representing concepts from traditional Ndebele music which continues to influence contemporary Ndebele musicians. Secondly, terms representing musical concepts which some Ndebele musicians have adopted from Shona traditional music also deserved inclusion. Finally, the dictionary had to include music terms representing concepts, be it of English, Italian, French and German origin, which are now central in the music domain. Either in the Ndebele term creation for the dictionary (Nkomo 2005) or the search for English and Shona translation equivalents, challenges were encountered because, as far as LSP lexicography is concerned, music is a highly culture-dependent domain (Bergenholtz and Tarp 1995). Thus, cultural knowledge was required in many instances as well as specialised music knowledge and linguistic competence to facilitate translation. It has already been indicated that music experts were helpful regarding specialised knowledge, but the editors also needed to develop competence to grasp and process that knowledge for lexicographic purposes. Linguistic competence in English and Shona was thus another important factor.

As far as English translation equivalents were concerned, the editors relied on their competence in English which is the main language of education in Zimbabwe. Furthermore, general monolingual, bilingual and music dictionar- 
ies in English were amply available for consultation throughout the compilation stage. Music experts who were members of the reference working group also evaluated the English translation equivalents to ensure that content was not seriously lost during translation.

Translation between Ndebele and Shona would be equally difficult as it appeared that there are certain musical concepts in Shona not found in Ndebele and vice versa. The editors' linguistic competence in Shona was also too limited for lexicographic purposes. Unlike in English, there were no appropriate dictionaries that could give assistance. Thus, the ISM editors could not determine the correct translation equivalents themselves. In fact, determining translation equivalence between Ndebele and Shona was more difficult than between Ndebele and English despite the fact that cultural distance is greater between the latter two. This meant that the editors had to rely heavily on their Shonaspeaking colleagues at ALRI. Conveniently, the editors of Duramazwi reMimhanzi (Mheta 2005), the Shona music terms dictionary, from their side needed similar assistance throughout the compilation of their dictionary. Nevertheless, the manifestation of the cultural factor and linguistic anisomorphism in the ISM remain evident as will be shown in Sections 5, 6 and 7.

Another matter which the editors had to contend with during and even after the compilation of the ISM pertains to the attitude of the users towards other languages. The attitude of Ndebele speakers towards other languages in Zimbabwe are discussed by Hadebe (2005) with reference to the prospects of a bilingual Ndebele-Shona/Shona-Ndebele dictionary and also by Ncube (2005) regarding loan words in the ISN. Both writers rightly indicate that these attitudes result from certain historical, economic and socio-political factors. Although they cannot be overstated, they surfaced during and after the production of the ISM. Some users, including some music practitioners who were members of the reference working group questioned the inclusion of translation equivalents, especially in Shona. They argued that a purely monolingual music dictionary should be compiled, especially following a major breakthrough in mother-tongue lexicography inaugurated by the successful publication of the ISN. Yet others questioned the manner in which transliteration was used to create Ndebele terms for some Shona and English music concepts. While lexicographic planning needs to be cognisant of such factors, it should ensure that appropriate and user-friendly dictionaries are ultimately produced. The typological nature of the ISM is best suited for the music industry and music education in Zimbabwe. Multilingualism is both a resource and a tool which needs to be developed in various spheres of Zimbabwean life. Lexicography can make significant contributions in this regard.

\section{The Frame Structure (Megastructure)}

Metalexicographic literature indicates that the central list bias in lexicographic practice, be it in the compilation or evaluation of dictionaries, is now disap- 
pearing. The 'word book structure' (Hausmann and Wiegand 1989) which regards the so-called 'outer texts' as functional text components of dictionaries has been adopted. Not only the word list is considered as the dictionary, but also the 'front matter' and 'back matter' texts. Accordingly, a dictionary is now regarded as a 'carrier of texts' (Wiegand 1996, Kammerer and Wiegand 1998). The resultant type of dictionary structure is called the 'frame structure' (Kammerer and Wiegand 1998) or the 'megastructure' (Hartmann and James 1998, Yong and Peng 2007). Various studies and publications by scholars such as Gouws (2002, 2004, 2007), Gouws and Prinsloo (2005), Tarp (2005), Bergenholtz and Nielsen (2006) and Yong and Peng (2007) demonstrate several ways in which the outer texts ought to complement the central list in the realisation of lexicographic functions. For the purpose of this section, it can simply be noted that the ISM conforms to this type of dictionary structure. It consists of the front matter (pp. i-xxvii), the central word list (pp. 1-124) and the back matter (pp. 125-195). In the remainder of the article, it will chiefly be demonstrated how these different text components complement each other in the dictionary.

\section{The Front Matter}

The front matter of the ISM contains the following text components:

(a) the title page,

(b) the imprint page,

(c) the contents page, Okumunyethweyo,

(d) the editorial and participants page, Abaphathekileyo,

(e) the preface, Isandulelo,

(f) the foreword, Isethulo,

(g) the acknowledgements, Amazwi Okubonga,

(h) the bibliography, Umthombo Wolwazi,

(i) the introduction, Isingeniso,

(j) the guide for the use of the dictionary, Okumele Kulandelwe Ngosebenza Isichazamazwi, and

(k) the editorial request, Isicelo Sabahleli.

Each of the ISM front matter components listed above falls within the distinct categories of integrated or non-/unintegrated outer texts (Gouws 2004). The distinction is based on whether the genuine purpose of the dictionary or any of its lexicographic functions which primarily occur in the central list are realised or complemented in a particular outer text. It is in the light of this distinction that the above front matter texts of the ISM will be discussed.

Gouws (2004: 72) describes the difference between these outer texts as follows:

Unintegrated outer texts complement the central list and are not needed to retrieve the information presented in the articles of the central list, neither do they 
add to the treatment of the subject matter of the dictionary. Integrated outer texts function in co-ordination with the central list and are aids in ensuring an optimal and full retrieval of information and an accomplishment of the genuine purpose.

The imprint page provides the bibliographic information about the dictionary. This includes its title (already given on the cover and title page), names of the editors, the publisher and the ISBN number. This information is useful for library cataloguing and database indexing, but not for using the dictionary and solving problems which motivate dictionary consultation. It is thus a typical example of an unintegrated outer text. It has nothing or very little to do with the contents of the dictionary, their access and use. The same would generally apply to the editorial and participants page, the preface, the foreword, the acknowledgements, the introduction and the editorial request pages, although this would depend on how much information related to the contents and use of the dictionary are included in a particular text. For example, because it was written by a board member of ALRI who was not closely involved in the actual production of the dictionary, the ISM foreword is less informative than the preface which was written by the coordinator of the ALLEX Project, or more so the introduction written by the editors.

On the other hand, the title page, the contents page, the bibliography page and the guide to dictionary use may be very helpful as far as the retrieval of information in the dictionary is concerned. Therefore, they fit into the category of integrated outer texts, which may be distinguished further as either functionadhering or non-function-adhering (Gouws 2007). Function-adhering outer texts are those from which lexicographic information may be retrieved to achieve a given lexicographic function which may not necessarily occur in the word list (Gouws 2007: 82). Those which do not contain lexicographic data but merely facilitate its access through guidance are integrated non-functionadhering outer texts. This description suits the title page, the contents page, the bibliography page and the guide to dictionary use as they provide guidance, but not information which may initiate a look-up procedure. In addition to describing how these texts work in the ISM, it is attempted to draw attention to how such texts may serve a more comprehensive purpose.

The title of the dictionary is its identity, just like the cover entries. According to Gouws and Prinsloo (2005: 165), cover entries "are not only there for promotional purposes or as a form of lexicographic cosmetics", but rather "functional entries" which "form an integral part of lexicographic presentation". Therefore, the title, as it appears on the front cover, the spine and title page of the dictionary, informs the user what to expect in the dictionary, for example, whether it is the most suitable for a particular consultation procedure or not. There being only three Ndebele dictionaries in circulation, the user who needs information about a music term would tell from the title that the ISM would be the best available dictionary. Gouws (2007) suggests that users would benefit more if the title page were to provide as its subtitle a hint of the lexicographic functions which the dictionary covers. Although this is not given in the ISM, it 
should be considered for future dictionaries, LSP dictionaries included. Still, the title page would remain an integrated non-function-adhering outer text.

The same would apply to the bibliography. The bibliography of the ISM lists the sources which provided terms, and definitional and etymological data contained in the dictionary. From these sources, users may obtain more comprehensive specialised and cultural music knowledge. However, since users obtain, except such guidance, no lexicographic information from the bibliography, it therefore remains an integrated non-function-adhering text. Such a text could be made more helpful if it were clearly linked to certain articles in the main text through cross-referencing. This would, as suggested by Nielsen (1999), enable the user to know the relevant source for a particular type of information.

The ISM guide to dictionary use (pp. xix-xxv) explains how the data contained in the dictionary and enumerated on the contents page may be accessed. The distribution of lexicographic data as well as their arrangement and use of lexicographic conventions is explained and illustrated by means of articles extracted from the main text. The following table is also part of the ISM guide to dictionary use.

Table 1: Symbols used in the ISM and their explanations (p. xxiv).

\begin{tabular}{|c|l|l|}
\hline UPHAWU (indicator) & NGESINDEBELE (Ndebele) & NGESILUNGU (English) \\
\hline$[\mathrm{]}$ & Enye indlela yokubiza igama & Variant enclosed \\
\hline$<>$ & Imbali yegama & Etymology enclosed \\
\hline FAN & Amagama alengcazelo ezifanayo & Synonyms \\
\hline BONA & Bona ingcazelo & Find meaning \\
\hline KHA & Khangela & Check or Compare \\
\hline$(\mathrm{SH})$ & Ligama lesiShona & Shona equivalent \\
\hline$(\mathrm{EN})$ & Ligama lesiLungu & English equivalent \\
\hline
\end{tabular}

The first column of Table 1 lists the symbols and abbreviations used in the ISM. The second column explains each symbol in Ndebele while the third provides English explanations. The article will deal with the use of these symbols and abbreviations in the sections which follow, especially Sections 6 and 8. While front matter texts have often been viewed as occupying valuable dictionary space, because users rarely refer to them, they play a crucial role even in the realisation of the genuine purpose and functions of the dictionary. This has been indicated by describing the ISM front matter texts according to the distinction between integrated and unintegrated (Gouws 2004) as well as functionadhering and non-function-adhering (Gouws 2007). Gouws (2007) argues that front matter texts are in fact consulted, although the frequency of their consultation may not be expected to equal that of the main text since users would read the guide to dictionary use once, but after having mastered its conventions, often continue to consult only the main text. The challenge for practising 
lexicographers, therefore, is to evince maximum caution in the planning and utilisation of the front matter texts for data distribution and user guidance.

\section{The Macrostructure}

This section describes the elements of the ISM macrostructure. It also highlights and explains the procedures adopted to formulate the macrostructure, the challenges encountered as well the counter-strategies employed in the process.

The macrostructure of the ISM consists of 1228 articles. The lexical items represent the conceptual and thematic structure of the music domain which is based on traditional Ndebele and contemporary Zimbabwean music. As a result, the macrostructure consists of indigenous and contemporary music terms. Indigenous music terms are mainly categorised as follows:

(a) Names of traditional dances such as isitshikitsha, ingquzu, indlamu, amajukwa and amantshomane.

(b) Names of traditional instruments such as umqangala (mouth bow), uphondo (horn) and izikeyi (wooden clappers).

(c) Names of traditional ceremonies in which music plays an important role such as iNxwala (first-fruits ceremony), umthethelo (ancestral appeasement ceremony), umbuyiso (home-bringing ceremony) and indunduzelo (initiation ceremony).

(d) Names of various types of traditional costume and attire such as amabhetshu (skin dress) imisisi (skin attire for women), indlukula (headgear), isidlodlo (headgear) and amahlwayi (leg-rattles).

(e) Names of music/song categories according to ceremonies and situations of rendition such as ingoma yeNxwala (first-fruits ceremony song), ingoma zokuzingela (hunting songs) and ingoma zokugiga (pounding songs).

Such terms represent the core of traditional music knowledge in Ndebele. Furthermore, terms representing contemporary music knowledge were lemmatised, since they are integral in the production, study, analysis and appreciation of music and hence future developments in the music domain. The Ndebele people are now exposed not only to traditional Ndebele music but also to Zimbabwean and international music. To provide for this reality, the production of the ISM had to, as stated in Section 2, consider borrowed terms from mainly Shona and English. A significant number of lexical items in the ISM are names of dances and instruments which Ndebele people learnt or borrowed from Shona. The adoption and adaptation of Shona terms which resulted from this interaction is illustrated in the following table: 
Table 2: Adoption and adaptation of Shona music terms into Ndebele

\begin{tabular}{|l|l|}
\hline Shona Term & Lemmatised ISM Term \\
\hline nyunganyunga/nyungwenyungwe & inyunganyunga/inyungwenyungwe \\
\hline nhare & inare \\
\hline muchongoyo & umtshongoyo \\
\hline jerusarema & ijerusalema \\
\hline kongonya & ikongonya \\
\hline shangara & ishangara \\
\hline mhande & imande \\
\hline mbira & imbila/imbira \\
\hline mbakumba & imbakumba \\
\hline magagada & amagagada \\
\hline maghavu & amagavu \\
\hline madhebhe & amadebhe \\
\hline
\end{tabular}

The first procedure for the adoption and adaptation of Shona terms into Ndebele is the prefixing of these terms with an initial vowel. This is in agreement with the morphological structure of nouns in the Nguni languages, of which Ndebele is one. By including an initial vowel as a pre-prefix, the ISM editors already took a significant step in adapting Shona terms to Ndebele morphology. As illustrated in Table 2, this is the most remarkable difference between the Ndebele terms and their Shona equivalents in the ISM.

However, the inclusion of an initial vowel alone before the prefix proper does not change all Shona terms into Ndebele. Some terms have sounds not fully accepted in Ndebele, while the sounds of others are represented differently in Ndebele. The trill [r] is one sound which is resisted in Ndebele although most speakers find it unavoidable in other words, some of which are borrowed from English. Instead of [r], some speakers would prefer the lateral [1]. As a result, $/ \mathrm{r} /$ and $/ 1 /$ in the fourth and fifth syllables respectively of the Shona term jerusarema and the Ndebele term ijerusalema (for an original type of Shona dance) distinguish the two terms. Although Ndebele borrowed this term from Shona, it should be noted that Shona adopted the Biblical 'Jerusalem' to name this traditional dance whose survival was severely threatened by the influence of early missionaries who found it obscene. Thus, it is actually Shona which rejected $/ 1 /$ in the fourth syllable of 'Jerusalem' in preference of $/ \mathrm{r} /$. In other cases, it is not only difficult but also futile to replace / $\mathrm{r} /$ with $/ 1 /$ because words become awkward and difficult to pronounce. In this regard, relevant examples from Table 2 are inare (a type of mbira), ishangara (a type of dance) and imbira (mbira). However, in the case of imbira, the term was treated as a variant of imbila which, according to music experts, is equally popular. What is interesting though is that imbila already existed in Ndebele, referring to a rabbit. If this does not cause problems in the music domain, the rephonologised term may become the standard term, but if it does, imbira will have to be fully 
accepted. This flexibility is provided for by a proscriptive lexicographic approach as opposed to purely prescriptive and descriptive approaches (Bergenholtz 2003, Tarp and Gouws 2008).

Another phonological and orthographic feature which the ISM editors had to deal with in the adaptation of Shona terms to Ndebele is the distinction between certain sounds and their breathy counterparts. Ndebele does not make this distinction, but Shona does by using the voiced glottal fricative [h]. Some of the sounds involved include the nasals [m] and [n], the voiced velar stop [g] and the voiced alveolar stop [d]. In Table 2, the Shona terms mhande (type of traditional dance) and nhare (type of mbira) contain the breathy voiced nasals $[\mathrm{m}]$ and [n] respectively. Adapting them to Ndebele resulted in imande and inare respectively. Although the two breathy nasals are realised in spoken Ndebele as in the first syllables of unina (his/her mother) and mana (stop) respectively, this phenomenon is not given special orthographic presentation as in Shona. In cases where $m h$ is realised in Ndebele writing, the pronunciation differs from that of Shona. For instance, in the word umhawu (jealousy), $m$ becomes a separate syllable as a contracted form for $m u$. Thus Mhangura (the name of a town) can be read in two completely different ways by a Ndebele and a Shona speaker. The adaptation of some Shona terms to Ndebele, therefore, included the dropping of $h$ from breathy nasals as it causes phonological inconsistencies in some instances. The same procedure was applied to the Shona terms maghavu (leg-rattles) and madhebhe (a type of mbira) which contain the breathy glottal stop [?] and the alveolar stop [d] respectively to result in amagavu and amadebhe.

For the adaptation of Shona terms to Ndebele the differences in the presentation of the voiceless palatal affricate [t $\mathrm{t}$ ] also had to be considered. In Shona, the sound is orthographically written as ch while it is rendered as tsh in Ndebele. As shown in Table 2, the Shona term muchongoyo (a type of traditional dance) becomes umtshongoyo in Ndebele. While the spelling ch exists in Ndebele, it is a dental click [I] as in -chitha (spill) or umchamo (urine). Thus, simply prefixing the Shona term muchongoyo with an initial vowel would produce a different pronunciation and fail to capture the meaning of the original term.

A fairly large number of lexical items in the ISM are terms borrowed from English. Similar principles of adopting and adapting English as those discussed previously in the case of Shona terms were used. Hadebe (2002: 138) points out that "a loanword might be accepted into the language as part of vocabulary growth ... or coined as a term and be accepted but has to fit in the Ndebele writing system". This remained an important factor in the adoption of music terms from English. Specifically, the challenges encountered pertained to what could have been misconceived as vowel sequencing when initial vowels were prefixed on vowel-commencing noun stems from English and other unacceptable sound clusters. The challenges of dealing with vowel-commencing noun stems is summarised in Table 3 below. 
Table 3: Lemmatising vowel-commencing adoptives from English in the ISM

\begin{tabular}{|l|l|l|l|l|}
\hline English Term & VSS & Hyphenated & Semi-vocalised & ISM Lemmata \\
\hline alto & ialitho & i-alitho & iyalitho & alitho \\
\hline encore & ienkho & i-enkho & iyenkho & enkho \\
\hline earphone & iiyefoni & i-iyefoni & iyiyefoni & iyefoni \\
\hline oboe & iobho & i-obho & iwobho & obho \\
\hline audition & iodishini & i-odishini & iwodishini & odishini \\
\hline organ & iogani & i-ogani & iwogani & ogani \\
\hline
\end{tabular}

As noted earlier, prefixing noun terms from Shona with initial vowels was the first step to adapting them to Ndebele orthography. This also applies to English terms and terms from other languages with a different noun structure. This seemingly simple procedure resulted in several lemmatisation dilemmas in the ISM with regard to adopted vowel-commencing English nouns like those in the first column of Table 3. The initial vowel, which is characteristic of nouns in Ndebele and other Nguni languages would result in orthographic words such as those in the second column of Table 3. The Ndebele orthography which needs updating does not permit vowel sequencing. Nouns with vowel-commencing stems are treated inconsistently by different writers, some of whom identify vowel sequencing in them. However, the reality is that vowel sequencing is impermissible within syllables and that what appears in the second column of Table 3 is not vowel sequencing but vowel-syllable sequencing (VSS). Although the ISM editors were fully aware of this, they had to avoid controversy, especially regarding a dictionary with a very limited user-group, by not adopting a strategy which was not even used in the ISN. Had it been used in the ISN, there would have been entries such as ioda (order), iorenji (orange) and ioyili (oil), which have, however, been lemmatised as iwoda, iworenji and iwoyili respectively. This involves the process of semi-vocalisation, whose results are presented in the fourth column of Table 3. By adopting this strategy, the ISN editors avoided yet another strategy used by many Ndebele writers, which consists of inserting a hyphen between the initial vowel and the adopted noun stem as shown in the third column of Table 3. Following the principles of the ISN, the ISM editors also avoided the use of the hyphen which is mainly employed in breaking compounds. Neither did they lemmatise the adoptives with semi-vowels bridging the perceived vowel sequences as the ISN editors have done. The reason for this is that semi-vocalisation is not predictable in all contexts. Blending the letters $i$ and $a$ may result in inserting either a $y$ or an $h$ so that the user may be uncertain whether to search the lemma using iy- or ih-. Relevant examples in the ISM regard the English terms alto, encore and earphone, which would be lemmatised as iyalitho, iyenkho and iyiyefoni respectively. Yet informal discussions with Ndebele linguists have indicated that ihalitho, ihenkho and ihiyefoni would have been better. In the ISM, only the rephonologised English stems were lemmatised without initial vowels as shown in the last column, thereby avoiding the problems associated with each of the first three strategies. 
The structure of the article headed by such lemmata is illustrated by the following example:

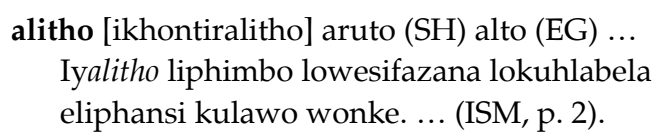

The access position of the adopted term in the macrostructure of the ISM is determined by the first letter of the vowel-commencing stem of the English term alto, as it is also the case in the English alphabetic equivalent register. Together with the statement in the front matter drawing users' attention to this exception to the rule that all noun terms are lemmatised according to their initial vowels, the alphabetic equivalent register may be useful in guiding users to the lemma type in question, given that the English terms are better known. Semi-vocalisation is then employed in the full-sentence definitions which include the defined lemmata. In the definitions of this type of lemmata under discussion, lemmata are preceded by initial vowels and semi-vocals. The definition of alitho in the exemplified article thus begins with 'Iyalitho ...' and the lemma is italicised as in the rest of the articles (see Section 6).

In addition to the challenge resulting from vowel-commencing English stems, there are yet other sound clusters in English which are problematic in Ndebele and had to be avoided in the borrowing process. For example, the adoptives from orchestra and quadrille were lemmatised okhesitira and ikhwadirili. While iokhestra and ikhwadrili respectively are realised in speech, their acceptance in writing is still contentious, so that the ISM editors had to avoid these representations. The problematic sound clusters in this regard are [str] and $[\mathrm{dr}]$ respectively.

In an attempt to represent contemporary musical knowledge in the ISM, loan translation was also used with the result that compound terms became part of macrostructural elements. Examples include amazwingoma from amazwi engoma, literally meaning 'words of a song' for lyrics and inqalakutsha from -qala kutsha, literally meaning 'a fresh start' for da capo.

Multi-lexical lexical items are also part of the ISM macrostructure. Terms such as ihubo lenkozo (chorale), ikhandensi ephanjanisiweyo (interrupted cadence), isikali somculo (musical scale) and isikali esincane (minor scale) are some examples. While the decision to include them was made at the initial planning stage, multi-word units posed a challenge that only surfaced at the final editorial stage carried out together with the publishing editor. Some lemmata appeared where they were least likely to be searched for in the alphabetic macrostructure, thereby posing a danger of making them less accessible to the users. For example, the users, as well as the editors, are likely to take it as a given that the article stretch including lemmata ranging from ingoma yeNxwala to ingoma zokuzingela would be preceded by articles headed by ingomabafi, ingomabusuku, ingomanyoni and ingomasililo. However, the computer interprets the space between compound words as a letter coming before the 
letter $a$. Accordingly, the multi-word units made an earlier alphabetic appearance than anticipated. However, although users may not fail to find such lemmata as they immediately follow the lemma ingoma, a statement in the front matter, especially in the guide to dictionary use, would have sufficed in drawing the users' attention to this fact.

The tonic solfa notes, namely $s, f, m, r, t, l, d$ and $d$, were entered as they are pronounced and sung to render them respectively as so, $\mathbf{f a}, \mathbf{m i}$, re, thi, la, do and do without initial vowels, just like terms with vowel-commencing stems as exemplified by alitho earlier on. Otherwise, the arrangement of lemmata in the ISM is strictly letter by letter, with spaces between words in multi-lexical items being treated as alphabetical letters.

\section{The Microstructure}

This section focuses on the structure of dictionary articles. Before looking at those articles with more data items, the structure of articles with the least number of data items is presented first. This presentation is accompanied by a discussion of structural indicators which facilitate information retrieval from the various data categories.

The following structure represents those articles with the least number of data items:

$$
\text { Lemma } \rightarrow \text { Shona Equivalent } \rightarrow \text { English Equivalent } \rightarrow \text { Definition }
$$

As in most dictionaries, bold print is used for lemmata so that they are distinct and therefore easy to find. As noted earlier, some terms have been created to represent concepts which are less known to Ndebele users with a low level of encyclopaedic competence. Such lemmata are important for presenting spelling information.

Since the dictionary intends to facilitate an understanding of musical concepts whose lemmata are represented primarily in Ndebele, definitions follow in terms of importance. The definitions explaining the concepts consist of full sentences. The term defined is italicised in the definition. In contradistinction to the ISN, not all words used in the definitions are entered and defined in the ISM since some are 'common words', not specifically musical terms, which users should know or could look up in the ISN. To give users more details about the music concepts, ISM definitions are longer and more encyclopaedic than those of the ISN. This becomes clear in cases where certain lexical items are lemmatised in both dictionaries. To achieve this, defining principles were formulated to ensure that terms for similar concept categories such as dances, music genres, instruments, ceremonies and various types of costumes are defined exhaustively and at the same time uniformly.

Shona and English equivalents give the ISM a trilingual dimension, but as noted earlier, not a trilingual dictionary typology. The indicators SH and EN, 
being abbreviations for Shona and English respectively, are used. Equivalents have been included because the cultures represented in Shona and English have affected Ndebele culture, the music domain being no exception. In some cases, the equivalent is more familiar to the users than the Ndebele lemmatised term. The reason for this is that the equivalents and the terms in the dictionary are not, as mentioned in Section 2, direct equivalents owing to the cultural factor and linguistic anisomorphism. This, as indicated in Section 7, is reflected in the equivalent registers of the dictionary.

Those articles with more data items are now dealt with. An ISM article with all data items that the dictionary provides would show the following structure:

Lemma $\rightarrow$ Variant $\rightarrow$ Shona Equivalent $\rightarrow$ English Equivalent $\rightarrow$ Etymology $\rightarrow$ Definition $\rightarrow$ Synonym $\rightarrow$ Comparative reference $\rightarrow$ Reference to illustrations

No article in the dictionary contains all the data items given in the above structure. The inclusion of a particular data item was determined by the type of term and the concept represented with a view to its value for the user. The value of the data items discussed regarding articles with the least number of microstructural entries is the same, even in those articles which give more data. Repeating a discussion of them is therefore unnecessary.

Where required, variants are provided after the lemma, enclosed in square brackets (refer to Table 1). They highlight the fact that the language is not standardised, so that transliterations may be rendered in more than one form. A good example is iphiyano [ipijano] for piano. Some Ndebele speakers pronounce this borrowed term with an aspiration as [ $\left.\mathrm{p}^{\mathrm{h}}\right]$ [iphijano] while others pronounce it without aspiration but as an ejective [p'] [ip'ijano]. The former rendition was defined as the main lemma and the latter by a cross-reference to the main lemma (see Section 8). This suggests to users which term is preferred while space is saved at the same time. Besides these instances, variants appear in the ISM as transliterations for some acronyms from English. Examples are isidi [idisiki] for compact disk and idakhapho [idisi] for da capo. The former is defined as the main lemma because it is more popular than the latter whose rendition in Ndebele is problematic. Instead of idisiki, the preference may have been for idiski which is written as it is pronounced, disregarding the [sk] sound combination which remains contentious in writing. This is different from the latter case where the transliteration of the fuller form was preferred to that of the acronym $D C$ which is used along with the full form.

Etymology was provided for musical concepts whose terms were adopted from English yet having either Greek, French, Latin or Italian origins. The information that users can retrieve includes the source language, the word form in that language and the literal meaning which elucidates the contemporary meaning of the term. IsiGirikhi, isiFurentshi, isiLathini and isiTaliyana re- 
spectively represent the four main source languages listed above. The following example illustrates this.

iligetsha ... ligature (EN) <IsiTaliyana: ligature 'okubambanisayo'> (that which links) ... (ISM, p. 39).

The provided etymological data enhances a better understanding of the term through the link that can be established from the literal meaning to the specialised meaning. For instance, ligature from the above example refers to a notation symbol which links the first note to the last one in a musical phrase. Literally it means "that which links", but in a musical sense it refers to a specific notation symbol.

Just like variants, synonyms in the ISM are partly the result of borrowing terms from English where transliterations are in a synonymous relationship with Ndebele coinages. Examples are ilizwi/phimbo/iphathi (part of polyphonic music) and umaqondisekude/irimothi (remote controller). There are also synonymous indigenous terms such as ingoma/iculo (song) and -haya/ -bonga (praise mainly through poetry). In all such cases where both terms seem to be equally familiar, the compilers could not prescribe by excluding one of the terms but only by treating one as the main term and the other as (a) lesser synonym(s) which is defined by 'FAN' (refer to Table 1).

Reference indicators or markers are also part of the ISM microstructure. These include instances where users are referred from one article to another to effect paradigmatic relations as in itshelo (cello) where users are referred to all other types of violins or from an article in the main list to the section containing illustrations in cases where a concept is illustrated.

As far as the data items constituting the structure of individual articles are concerned, their provision depends largely on the term involved and the concept it represents. Information is provided in order to meet user needs in respect of a particular term but this provision is systematic for related terms. Once users learn the communicative significance of structural indicators, which are explained in the front matter, they can consistently apply it to all related articles.

\section{The Back Matter}

The back matter of the ISM contains four major sections in the following order: the section containing illustrations, Imifanekiso, the section containing songs, Ingoma ezikhethiweyo, the Shona alphabetic equivalent register, Amagamanhloko ngesiShona, and the English alphabetic equivalent register, Amagamanhloko ngesiLungu. These sections, which complement the main text can easily be accessed through the contents page. In the way in which they complement the central text, they may, just like the front matter texts, be understood according to the distinctions between integrated versus non-integrated outer texts on the one 
and function-adhering versus non-function-adhering outer texts on the other hand.

Illustrations serve to elucidate some of the concepts whose terms are lemmatised and defined in the central list. They are not just meant to brighten or enliven the dictionary. A cross-reference link is provided between illustrated terms and their illustrations. The section containing songs illustrates the practical use of the music notation symbols whose terms are lemmatised and defined in the central list. The mediostructure also facilitates the user search path between the main text and this section since the notations are named and defined in the main text. Thus, both the section containing illustrations and the section containing songs are integrated function-adhering outer texts.

Being in the access alphabetical order, the alphabetic equivalent registers, also called reverse indices, guide users not familiar with the Ndebele terms for the alphabetised Shona and English terms to the central list in which the Ndebele terms are lemmatised. This is necessary because some of these Ndebele terms were created for the first time during the production of the ISM. As indicated in Section 7, the alphabetic equivalent registers make the dictionary polyaccessible. However, it should be noted that in the many cases where direct equivalence does not exist, the equivalents are mainly explanatory and sometimes very brief paraphrases of the Ndebele terms. In the Shona register, mutambo wechinyakare has more than 20 different types of traditional dances recognised in Ndebele, while English has more than twice this number for traditional dance. Still, the information contained in the equivalent register may suffice for dictionary consultations whereby the user just wants to know the equivalent. In this way, the alphabetic equivalent registers are also integrated function-adhering outer texts.

\section{The Mediostructure}

Cross-referencing is a useful lexicographic device which is an integral component of the access structure. It guides the dictionary-user from one point to another for more information or for comparison. Cross-referencing can be explicit or implicit: in the former, the user is clearly advised or commanded to go to another point in the dictionary, while in the latter, the user is made to feel the need to go to another point without clear advice or command (Gouws and Prinsloo 1998, 2005; Louw 1999; Yong and Peng 2007).

Explicit cross-referencing was employed in the ISM in the following cases:

(a) Between synonyms whereby lesser synonyms are defined using other terms which would be more preferable. 'FAN' (refer to Table 1) is employed to link the more preferable lemma to its synonyms which the preferable lemma defines. For instance, 'FAN' -khalisa in the article corresponding to the lemma -tshaya (play a musical instrument or gadget) informs the user that while the two terms are synonymous, -tshaya is the 
more preferable term. The term -khalisa is then defined using -tshaya which directs the user to the more informative article for the meaning.

(b) Between variants whereby a less popular variant is defined using a more popular one. A less popular variant is enclosed in square brackets immediately after the main form as in ipansula [isipansula] (a dance). The term isipansula is then linked to the main form using the guide word 'BONA' which directs the user to ipansula which has been given a more comprehensive lexicographic treatment.

(c) From terms to illustrations whereby users are advised to refer to the section containing illustrations for a picture of an instrument, a piece of costume or a musical notation symbol. 'BONA umfanekiso' (SEE the illustration) at the end of the article corresponding to the lemma isikali esikhulu (major scale) (ISM, p. 73) advises the user to refer to the diagrammatic illustration of the major scale for effective conceptualisation.

(d) Between terms denoting concepts which are in a paradigmatic relationship, the user is advised through 'KHA' (refer to Table 1) to compare the term ivayola (viola), for instance, with ivayolini (violin), itshelo (cello) and ibhesimbili (double bass) which denote the other types of violins (ISM, p. 86). Unlike 'BONA', 'KHA' is not obligatory since all the necessary information on the term would be given in the reference article. Cross-referencing in such a case gives information that is not sought in the initial look-up process although it may benefit the user.

Implicit cross-referencing may be noted in cases where the user is not explicitly advised to refer, but may feel the need to do so, such as in the following:

(a) From the illustrations, especially of musical notation symbols to selected songs and vice versa. After moving from a term denoting a musical symbol, the user may refer to illustrations and proceed to check how the symbol is used in the selected songs. The user may also start from a particular song in the section containing songs, then check the symbol under the illustrations and eventually go to the main text to find out how it is used in singing.

(b) From the alphabetic equivalent registers to the main text whereby a user who may know the English or Shona term may start from the English or Shona alphabetic equivalents respectively to find out what a concept is called in Ndebele. The user may then proceed to the main text to find more information on the concept in Ndebele. This would be a case of the user taking advantage of the poly-accessible structure of the dictionary.

(c) From the ISM to other references outside the dictionary whereby the user may go through the list of references (dictionaries and other books) entitled Umthombo Wolwazi (p. xv) to obtain extra details which the dic- 
tionary could not provide. This is called dictionary external cross-referencing since access to the reference address involves exceeding the boundaries of the dictionary in use (Gouws and Prinsloo 2005: 180).

\section{Conclusion}

This article has given some insights into the production of the Ndebele music terms dictionary, Isichazamazwi SezoMculo (also referred to as the ISM). It has also outlined the structure of the dictionary, especially regarding dictionary contents, their distribution and presentation. It has been shown that the dictionary was compiled within the parameters of lexicographic principles, taking cognisance of the users' reference needs and skills. Thus, the resultant dictionary structure is not just a case of convention or a form of lexicographic cosmetics, but a vital component of dictionary planning which was intended to facilitate both data presentation and data retrieval. It is a mode of lexicographic communication. The article by no means claims that the ISM structure is without limitations as indications are given of how the dictionary could have been made more user-friendly. A critical analysis of the ISM by dictionary users and other metalexicographers might offer insights which may be useful for future LSP lexicography in Ndebele and other African languages. The insights may also be of value to lexicography in general.

\section{References}

Bergenholtz, H. 2003. User-oriented Understanding of Descriptive, Proscriptive and Prescriptive Lexicography. Lexikos 13: 65-80.

Bergenholtz, H. and S. Nielsen. 2006. Subject-field Components as Integrated Parts of LSP Dictionaries. Terminology 12 (2): 281-303.

Bergenholtz, H. and S. Tarp. 1995. Manual of Specialised Lexicography. Amsterdam: John Benjamins.

Bergenholtz, H. and S. Tarp. 2003. Two Opposing Theories: On H.E. Wiegand's Recent Discovery of Lexicographic Functions. Hermes: Journal of Linguistics 31: 171-196.

Burkhanov, I. 2004. Requirements for an "Ideal" Bilingual L1-L2 Translation-Oriented Dictionary. Lexikos 14: 17-32.

Gouws, R.H. 1996. A Sequence for Meeting Lexicographic Needs. Lexicography as a Financial Asset in a Multilingual South Africa: 97-110. Pretoria: Department of Arts, Culture, Science and Technology.

Gouws, R.H. 2002. Using a Frame Structure to Accommodate Cultural Data. Emejulu, J.D. (Ed.). 2002. Éléments de Lexicographie Gabonaise. Tome II: 54-69. New York: Jimacs-Hillman Publishers.

Gouws, R.H. 2004. Outer Texts in Bilingual Dictionaries. Lexikos 14: 67-88.

Gouws, R.H. 2004a. Monolingual and Bilingual Learners' Dictionaries. Lexikos 14: 264-274.

Gouws, R.H. 2007. A Transtextual Approach to Lexicographic Functions. Lexikos 17: 77-87.

Gouws, R.H and D.J. Prinsloo. 1998. Cross-referencing as a Lexicographic Device. Lexikos 8: 17-36. 
Gouws, R.H. and D.J. Prinsloo. 2005. Principles and Practice of South African Lexicography. Stellenbosch: SUN PReSS.

Hadebe, S. 2002. The Standardisation of the Ndebele Language through Dictionary Making. Unpublished D.Phil. Dissertation. Harare/Oslo: University of Zimbabwe/University of Oslo.

Hadebe, S. 2005. Reflections on the Proposed Ndebele-Shona/Shona-Ndebele Dictionary. Lexikos 15: 265-275.

Hadebe, S. et al. (Eds.). 2001. Isichazamazwi SesiNdebele. Harare: College Press.

Hartmann, R.R.K. 1983. Lexicography: Principles and Practice. London: Academic Press.

Hartmann, R.R.K. and G. James. 1998. Dictionary of Lexicography. London/New York: Routledge.

Hausmann, F.J and H.E. Wiegand. 1989. Component Parts and Structures of General Monolingual Dictionaries: A Survey. Hausmann, F.J. et al. 1989-1991. Wörterbücher. Ein internationales Handbuch zur Lexikographie/Dictionaries. An International Encyclopedia of Lexicography/Dictionnaires. Encyclopédie internationale de lexicographie. Berlin/New York: Walter de Gruyter.

Kammerer, M. and H.E. Wiegand. 1998. Über die textuelle Rahmenstruktur von Printwörterbüchern. Präzisierungen und weiterführende Überlegungen. Lexicographica: International Annual for Lexicography 14: 224-238.

Louw, P.A. 1999. Access Structures in a Standard Translation Dictionary. Lexikos 9: 108-118.

Mheta, G. (Ed.). 2005. Duramazwi reMimhanzi. Gweru: Mambo Press.

Ncube, C. 2005. Language Development or Language Corruption: A Case of Loan-words in Isichazamazwi SesiNdebele. Lexikos 15: 294-305.

Nielsen, S. 1999. Mediostructures in Bilingual LSP Dictionaries. Lexicographica: International Annual for Lexicography 15: 91-113.

Nkomo, D. 2005. Compiling Specialised Dictionaries in African Languages: Isichazamazwi SezoMculo as a Special Reference. Zambezia: The Journal of Humanities of the University of Zimbabwe 32 (1-2): 64-77.

Nkomo, D. and N. Moyo (Eds.). 2006. Isichazamazwi SezoMculo. Gweru: Mambo Press.

Pelling, J.N. 1966. A Practical Ndebele Dictionary. Harare: Longman Zimbabwe.

Svensén, B. 1993. Practical Lexicography: Principles and Methods of Dictionary-Making. Oxford: Oxford University Press.

Tarp, S. 2000. Theoretical Challenges to Practical Specialised Lexicography. Lexikos 10: 189-208.

Tarp, S. 2002. Basic Elements of a Lexicographic Theory. Emejulu, J.D. (Ed.). 2002. Éléments de Lexicographie Gabonaise. Tome II: 7-20. New York: Jimacs-Hillman Publishers.

Tarp, S. 2004. Basic Problems of Learners' Lexicography. Lexikos 14: 222-252.

Tarp, S. 2005. The Pedagogical Dimension of a Well-Conceived Specialised Dictionary. Iberica: Journal of European Languages for Specific Purposes 10: 7-21.

Tarp, S. and R.H. Gouws. 2008. A Lexicographic Approach to Language Policy and Recommendations for Future Dictionaries. Lexikos 18: 232-255.

Wiegand, H.E. 1996. A Theory of Lexicographical Texts. An Overview. South African Journal of Linguistics 14(4):134-149.

Yong, J. and H. Peng. 2007. Bilingual Lexicography from a Communicative Perspective. Amsterdam/ Philadelphia: John Benjamins. 